\title{
Effect of dexamethasone on daily fetal movement, umbilical and middle cerebral arteries Doppler and cardiotocogram
}

\author{
Ahmed Alanwar*, Sherif Akl, Sherif Hanafi, Nader Mohamed
}

Ain Shams Maternity Hospital, Faculty of Medicine, Ain Shams University, Cairo, Egypt

Received: 29 August 2021

Revised: 01 October 2021

Accepted: 02 October 2021

\section{*Correspondence:}

Dr. Ahmed Alanwar,

E-mail: eladwar@hotmail.com

Copyright: () the author(s), publisher and licensee Medip Academy. This is an open-access article distributed under the terms of the Creative Commons Attribution Non-Commercial License, which permits unrestricted non-commercial use, distribution, and reproduction in any medium, provided the original work is properly cited.

\begin{abstract}
Background: Preterm birth is a leading cause of perinatal death and disability and is an important public health problem globally. There is more work to be done regarding steroids effect, especially with the variations among demography and pathological conditions affecting mothers. The aim of this study was to investigate the effect of dexamethasone on healthy fetuses, observing the effects on MCA and UA Doppler velocity waveforms and cardiotocography, correlating them with fetal movement.

Methods: This prospective cross-sectional study was conducted in Ain Shams University Maternity Hospital, starting from April 2020 till December 2020. One hundred and ten women was recruited for the study. All women undergo elective cesarean section before 39 weeks of gestation. UA and MCA Doppler values were taken; nonstress test was recorded and fetal movements were counted after a single course of dexamethasone.

Results: Our results included decrease in MCA PI, decrease in foetal movement count on the second day of dexamethasone injection, increase of short-term variability and direct correlation between the MCA RI and UA PI with the fetal movements decrease on the $5^{\text {th }}$ day of dexamethasone injection.

Conclusions: There are definitely cardiovascular changes that occur after dexamethasone administration, presented by increase in MCA blood flow and increase in FHR short term variability.
\end{abstract}

Keywords: Dexamethasone, Fetal movement, Middle cerebral artery Doppler, Umbilical artery Doppler

\section{INTRODUCTION}

Preterm birth occurs most commonly in economically low communities. Therefore, corticosteroid therapy, could be used as a measure of decreasing foetal morbidities and mortalities while remaining relatively an inexpensive method. It was found that the administration of certain corticosteroids to women at risk of preterm delivery reduces the risks of complications of prematurity such as combined foetal and neonatal death, respiratory distress syndrome, cerebroventricular haemorrhage, necrotizing enterocolitis, systemic infections, and childhood developmental delay. Benefits were found when treatment was commenced between 26 and 35 weeks of gestation, and for babies born 1-7 days after commencing treatment. ${ }^{1}$
Regarding regimens, single course regimen is considerably reassuring, while it is fairly evident that the repeated courses relate to some harmful effects such as increased sepsis in PPROM, restricted foetal body and brain growth, adrenal suppression, and neonatal death. ${ }^{2}$

Along with the progress of such studies regarding prematurity, came along a very important question about the side effects of corticosteroids on the influenced foetus.

The investigation for this matter started shortly after the conclusion made by Liggins and Howie. ${ }^{3}$ Maršál and his team worked on foetal breathing movements and concluded no changes. ${ }^{4}$ Katz et al worked with different diagnostic modalities, and exploited cardiotocography and 
Doppler studies to detect changes. ${ }^{5}$ These studies however were concentrated on betamethasone.

While aforementioned studies explored intrauterine foetal changes with corticosteroids influence, some other studies observed the new-born foetuses and long-term effects on children. It has to be emphasized that there has been a considerable difference between the use of one course and multiple courses. Doyle et al studied the effect on children at age of 14 years old who were exposed to at least one course of corticosteroid, and they concluded that there is no apparent risk of an adverse neurodevelopment outcome associated with antenatal corticosteroid use. ${ }^{6}$ However, Wapner et al found a reduction in birth weight and an increase in small for gestational age infants, especially after four courses of corticosteroids. ${ }^{7}$

\section{METHODS}

\section{Study type, place, and period}

This prospective cross-sectional study was conducted in Ain Shams University Maternity Hospital, Egypt, from April 2020 till December 2020.

\section{Sample size calculation}

MedCalc ${ }^{\circledR}$ version 12.3.0.0 program was used for calculations of sample size, statistical calculator based on $95 \%$ confidence interval and power of the study $80 \%$ with $\alpha$ error $5 \%$, According to a previous study Jackson et al, showed that the biophysical profile scores were reduced in $28 \%$ of the study population after betamethasone administration $(\mathrm{p}<0.05) .{ }^{8}$ Amniotic fluid index on day 3 was decreased from baseline in $72 \%$ of patients after betamethasone administration $(\mathrm{p}<0.05)$. Forty-four per cent of patients reported a decrease in fetal movement. Of these patients, $87 \%$ had a decreased amniotic fluid index when compared to baseline $(\mathrm{p}<0.05)$. So it can be relied upon in this study, based on this assumption, sample size was calculated according to these values produced a minimal samples size of 105 cases were enough to find such a difference. Assuming a drop-out ratio of 5\%, the sample size will be 110 cases.

\section{Selection criteria of the patients}

One hundred and ten pregnant women were recruited for this study, all pregnant women undergo elective cesarean section before 39 weeks of gestation. Women who previously received a corticosteroid course, women with medical disorders which can compromise and alter Doppler readings, such as diabetes mellitus or pregnancy induced hypertension, women with obstetric complications, such as placenta previa or preterm premature rupture of membranes, women with fetal complications such as congenital anomalies or IUGR are excluded from the study. Informed written consent was obtained from all participants before recruitment in the study, and after explaining the purpose and procedures of the study and possible risks.

\section{Procedure}

All women received dexamethasone sodium phosphate ampoules $(8 \mathrm{mg})$. The course was $3 / 4$ ampoule $(6 \mathrm{mg})$ intramuscularly, every 12 hours, for 48 hours (4 does). All women are followed for 6 days after dexamethasone injection.

Day zero; UA and MCA Doppler values were taken; nonstress test was recorded at the clinic. We used the parameters of normal nonstress test of the American College of Obstetricians and Gynecologists (ACOG Practice Bulletin, 2014). ${ }^{9}$ Participants were instructed to start counting fetal movements as soon as they went home, Sadovsky method was employed. ${ }^{10} 1^{\text {st }}$ dose of dexamethasone was to be taken at $10 \mathrm{pm}$ that day. Day 1; women continue counting movement throughout the day, $2^{\text {nd }}$ dose dexamethasone was received at $10 \mathrm{am}$, and $3^{\text {rd }}$ dose was received at $10 \mathrm{pm}$. Day 2; women continued counting movement throughout the day, $4^{\text {th }}$ dose was received at $10 \mathrm{am}$. Day 3; women came to the clinic at 12 $\mathrm{pm}$ (which is considered more than 24 hours after last dose, or 60 hours since the first dose), UA and MCA Doppler values were taken, and nonstress test was recorded. Day 4, 5 and 6; Women continued counting movement throughout the day.

\section{Statistical analysis}

The collected data was, tabulated, and statistically analysed using SPSS program (Statistical Package for Social Sciences) software version 20.0.

Descriptive statistics were done for numerical parametric data as mean \pm SD (standard deviation) and minimum and maximum of the range and for numerical nonparametric data as median and $1^{\text {st }}$ and $3^{\text {rd }}$ inter-quartile range, while they were done for categorical data as number and percentage.

Inferential analyses were done for quantitative variables using independent t-test in cases of two independent groups with parametric data and Mann Whitney U in cases of two independent groups with non-parametric data.

Receiver operating characteristic (ROC curve) analysis was used to find out the overall predictivity of parameter in and to find out the best cut-off value with detection of sensitivity and specificity at this cut-off value.

Inferential analyses were done for qualitative data using Chi square test for independent groups. The level of significance was taken at $p$ value $<0.050$ as significant, otherwise non-significant. The $\mathrm{p}$ value is a statistical measure for the probability that the results observed in a study could have occurred by chance. 


\section{RESULTS}

Table 1 shows that mean \pm SD of age was $29.0 \pm 3.2$, of BMI was $27.5 \pm 1.3$, while that of GA was $38.3 \pm 1.2$. Two thirds of the studied cases were multiparous.

Table 1: Demographic characteristics of the studied cases $(\mathrm{N}=110)$.

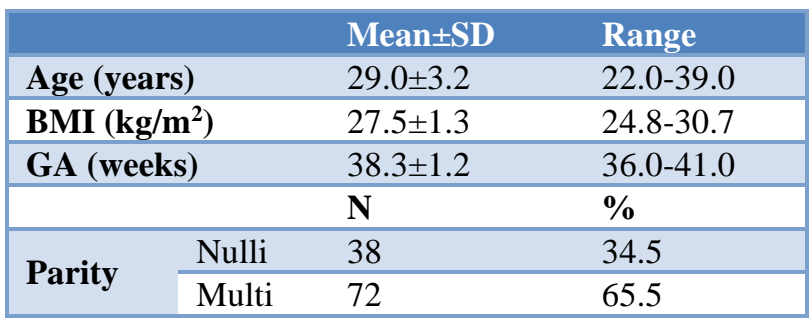

Table 2: Umbilical artery RI among studied cases.

\begin{tabular}{|llll|}
\hline Time & Mean \pm SD & Range & P value \\
\cline { 1 - 2 } Before & $0.65 \pm 0.03$ & $0.58-0.72$ & \\
\cline { 1 - 2 } After & $0.63 \pm 0.13$ & $0.24-0.93$ & \multirow{2}{*}{0.241} \\
\hline Change & $-0.01 \pm 0.12$ & $-0.37-0.25$ & \\
\hline
\end{tabular}

Total $=110$, change $=$ After-before (negative values indicate reduction), ^^aired t-test

Table 2 shows that umbilical artery RI did not show statistically significant change after dexamethasone intake.

Table 3: Umbilical artery PI among the studied cases.

\begin{tabular}{|llll|}
\hline Time & Mean \pm SD & Range & P value \\
\cline { 1 - 3 } Before & $0.95 \pm 0.04$ & $0.82-1.05$ & \\
\cline { 1 - 3 } After & $0.92 \pm 0.21$ & $0.46-1.38$ & \\
\cline { 1 - 3 } Change & $-0.03 \pm 0.20$ & $-0.49-0.50$ & \\
\hline
\end{tabular}

Total $=110$, change $=$ After-before (negative values indicate reduction), ^Paired t-test

Table 3 shows that umbilical artery PI did not show statistically significant change after dexamethasone intake.

Table 4: Middle cerebral artery RI among the studied cases.

\begin{tabular}{|c|c|c|c|}
\hline Time & Mean \pm SD & Range & P value \\
\hline Before & $0.72 \pm 0.05$ & $0.56-0.88$ & \multirow{3}{*}{$<0.001^{*}$} \\
\hline After & $0.68 \pm 0.10$ & $0.40-0.87$ & \\
\hline Change & $-0.03 \pm 0.11$ & $-0.30-0.14$ & \\
\hline
\end{tabular}

Total $=110$, change $=$ After-before (negative values indicate reduction), ^Paired t-test, *Significant

Table 4 show that middle cerebral artery RI showed statistically significant reduction after dexamethasone intake.

Table 5 show that: middle cerebral artery PI showed statistically significant reduction after dexamethasone intake.
Table 5: Middle cerebral artery PI among the studied cases

\begin{tabular}{|llll|}
\hline Time & Mean \pm SD & Range & P value \\
\cline { 1 - 2 } Before & $1.96 \pm 0.19$ & $1.54-2.40$ & \\
\cline { 1 - 3 } After & $1.71 \pm 0.28$ & $1.11-2.44$ & \\
\cline { 1 - 3 } Change & $-0.26 \pm 0.20$ & $-0.70-0.22$ & \\
\hline
\end{tabular}

Total $=110$, change $=$ After-before (negative values indicate reduction), ^Paired t-test, *Significant

Table 6: Heart rate (beat/minute) among the studied cases.

\begin{tabular}{|llll|}
\hline Time & Mean \pm SD & Range & P value \\
\cline { 1 - 3 } Before & $139.5 \pm 5.7$ & $126.0-155.0$ & \\
\cline { 1 - 3 } After & $140.2 \pm 8.8$ & $112.0-162.0$ & \\
\cline { 1 - 3 } Change & $0.7 \pm 6.1$ & $-14.0-17.0$ & \\
\hline
\end{tabular}

Total $=110$, change $=$ After-before (negative values indicate reduction), ^Paired t-test

Table 6 shows that heart rate did not show statistically significant change after dexamethasone intake.

Table 7: long term variability LTV (beats) among the studied cases.

\begin{tabular}{|llll|}
\hline Time & Mean \pm SD & Range & P value \\
\hline Before & $4.2 \pm 0.6$ & $3.0-5.0$ & \\
\cline { 1 - 2 } 0 & 0.672 \\
\hline Change & $0.0 \pm 0.4$ & $2.0-5.0$ & $-2.0-1.0$ \\
\end{tabular}

Total $=110$, change $=$ After-before (negative values indicate reduction), ^Paired t-test

Table 7 shows that long term variability (LTV) did not show statistically significant change after dexamethasone intake.

Table 8: Fetal movements among the studied cases.

\begin{tabular}{|c|c|c|c|c|}
\hline Time & & Mean \pm SD & Range & P value \\
\hline Before & & $11.9 \pm 0.7$ & $10.0-13.0$ & -- \\
\hline \multirow{2}{*}{ Day 1} & Level & $11.8 \pm 0.9$ & $9.0-13.0$ & \multirow{2}{*}{0.184} \\
\hline & Change & $-0.1 \pm 1.1$ & $-3.0-2.0$ & \\
\hline \multirow{2}{*}{ Day 2} & Level & $10.9 \pm 0.9$ & $8.0-14.0$ & \multirow{2}{*}{$<0.001 *$} \\
\hline & Change & $-1.0 \pm 1.1$ & $-3.0-2.0$ & \\
\hline \multirow{2}{*}{ Day 3} & Level & $11.8 \pm 0.8$ & $10.0-14.0$ & \multirow{2}{*}{0.360} \\
\hline & Change & $-0.1 \pm 1.0$ & $-3.0-3.0$ & \\
\hline \multirow{2}{*}{ Day 4} & Level & $11.9 \pm 0.8$ & $10.0-14.0$ & \multirow{2}{*}{0.929} \\
\hline & Change & $0.0 \pm 1.1$ & $-3.0-3.0$ & \\
\hline \multirow{2}{*}{ Day 5} & Level & $11.9 \pm 0.9$ & $9.0-14.0$ & \multirow{2}{*}{0.676} \\
\hline & Change & $0.0 \pm 1.1$ & $-4.0-3.0$ & \\
\hline \multirow{2}{*}{ Day 6} & Level & $11.8 \pm 0.8$ & $10.0-14.0$ & \multirow{2}{*}{0.350} \\
\hline & Change & $-0.1 \pm 1.1$ & $-3.0-3.0$ & \\
\hline
\end{tabular}

Total $=110$, change $=$ After-before (negative values indicate reduction), ^Paired t-test, *Significant

Table 8 shows that fetal movements did not show statistically significant change after dexamethasone intake except significant reduction at day 2 . 


\section{DISCUSSION}

Our study comes out with similar conclusions to many others, specifically the MCA PI, STV and foetal movements. It should be emphasized that for further care in our study to eliminate any bias, we chose women who almost had no risks on their foetuses.

We had the following outcome: decrease in MCA PI, decrease in foetal movement count on the second day, increase in short term variability, direct correlation between the short-term variability and gestational age (coincidental finding).

To complete the diagnostic modalities, Senat et al studied the effect of dexamethasone on Doppler velocity waveforms. ${ }^{11}$

Baud et al retrospectively analysed 883 live born infants and found that dexamethasone is associated with increased risk of periventricular leukomalacia, even more than mothers who didn't receive steroids during pregnancy. ${ }^{12}$

The prospective diagnostic modalities used in these studies have been long known for being the principal indicator for foetal wellbeing.

For instance, the use of Doppler studies in the 60's has evolved to be one of the hallmarks of calculating the flow of blood in foetal circulation. The work of Rushmer and Baker lead these studies. ${ }^{13}$ It has become an indicator for the well-being of foetus; therefore, it was used extensively in the search for steroid effects.

Chitrit et al made a study of 26 women, whom were in risk, including premature contractions, pre-eclampsia, and small for gestational age foetuses, placenta previa, intrahepatic cholestasis, PPROM and polyhydramnios. The dose varied from our study, as it was $4 \mathrm{mg}$ for 6 doses, not $8 \mathrm{mg}$ for 4 doses. ${ }^{14}$ Chitrit et al followed Doppler measurements for 1 week, at 0 hour, 48 hours, 96 hours, and 168 hours. ${ }^{14}$ They had a significant drop in the MCA PI after 4 days of 0.28 and a p value $<0.001$, and no significant changes were found in UA PI values. In our study, we followed up foetuses between the $60^{\text {th }}$ and the $72^{\text {nd }}$ hour, but not on the $96^{\text {th }}$ hour, and still we have experienced this MCA PI drop, with a mean difference of 0.23 . Which contrasts with our study.

Similarly, Urban et al conducted a study with 67 women at risk of preterm labour, as a comparison between dexamethasone and betamethasone. ${ }^{15}$ Thirty-four women received dexamethasone, but received the same dose as in our study, which is a $6 \mathrm{mg}, 4$ doses course. Follow up was done at 0, 24 and 72 hours from first dose, and the team recorded a drop in the MCA PI values of 0.32 from the mean MCA PI after 72 hours, with a $p$ value of 0.0001 . No significant change could be observed in the umbilical artery Doppler values. It is worth mentioning that 18 of the
34 women received tocolytics, which contrasts with our study.

The only study which didn't record a significant decrease in the MCA PI was conducted by Senat and Ville, but it was conducted solely on growth retarded foetuses. ${ }^{16}$ However, the team stated, that nonetheless, there was a decrease recorded, but it wasn't significant enough.

Senat and Ville proclaimed that the decrease continued for days, even after the course was stopped, between 96 and 168 hours. ${ }^{16}$ This might be explained by the blood redistribution because of the growth retardation, according to their analysis.

Apparently, our study had the same results in relation to Doppler values. But maybe it asserts the previous findings, especially that there aren't many studies about the Doppler changes with dexamethasone in particular. Perhaps through this mode of diagnosis, an early indicator for periventricular leukomalacia could be formulated, since Fukuda et al proved, that these cases have a decrease in cerebral blood flow velocity. ${ }^{17}$

Regarding the FHR pattern, we had a limitation which is the absence of CTG computerized numerical analysis. This fact rendered the reliance on visual interpretation of cardiotocography, and the presentation of some data in a qualitative manner, subjective. We used the format of 20 minutes as a unified time frame for all CTG traces. However, even with these limitations, our results were still in the proximity of other teams' works.

Except for Subtil et al and Magee et al, all other studies, like ours, found no significant changes in baseline foetal heart rate. ${ }^{18,19}$ These two studies didn't have different methods, only one of them had assigned data differently. Magee et al data had been presented differently, since they had 2 groups: one for dexamethasone and one for betamethasone. ${ }^{19}$ Strikingly, each group on its own didn't show significant decrease in foetal heart rate. But combining them together, gave a solid decrease at the $24^{\text {th }}$ hour with a $\mathrm{p}<0.0001$. Subtil et al made similar comparison between groups, but they were 3 groups. ${ }^{18}$ One group was given betamethasone acetate and phosphate, one was given betamethasone phosphate only, and the last was given dexamethasone. They conclude that the results were similar for the 3 groups.

They stated significant decrease in foetal heart rate at 32 hours, but also an increase at 80 hours, making it the only study that recorded a significant increase in foetal heart rate in consequence to dexamethasone administration.

In our study, we also recorded an increase in the baseline foetal heart rate, but it failed to produce a statistical significance.

Regarding the FHR variability, the studies vary greatly. Senat et al and Mushkat et al found no change in FHR 
variability. ${ }^{11,20}$ Mushkat et al used visual interpretation of CTG strips, in contrast to all other work teams. ${ }^{20}$ Senat et al study was a comparison between dexamethasone and betamethasone and concluded there were no changes in FHR variability in contrast to a significant decrease with betamethasone. $^{11}$

Multon et al conducted a study on growth retarded foetuses only, and still found no change with dexamethasone, or with betamethasone regarding FHR variability. ${ }^{21}$

In the other hand, the first 3 studies from 1994 to 1997 on Dexamethasone concluded an actual increase in the FHR STV. Dawes concluded that dexamethasone administration normally causes a rise in foetal heart rate variation for up to a day. ${ }^{22}$ This rise is reduced in preeclampsia or intrauterine growth retardation, associated with a reduction in umbilical flow, perhaps because of a consequential lower concentration of steroid in the foetus.

Magee et al, like the baseline results, had to combine both steroids into one group to show significance in increased FHR STV. ${ }^{19}$ Interestingly, Magee et al attributed the increase in STV to the time of CTG recording. ${ }^{19}$ They mentioned Dawes and Derks et al studies for comparison..$^{22,23}$ The patients described by Dawes received steroids first thing in the morning and had traces repeated at the same time on subsequent days; short term variation was found to be increased on day one, as confirmed in this trial. $^{22}$

In contrast, Derks et al administered steroid at 18:00 hours and then performed CTG traces between 10:00 hours and 16:00 hours on subsequent days; the short-term variation was found to be significantly decreased by day two. ${ }^{23}$ Although Derks et al said that there was a downward trend on day one, it is possible that the peak in short term variation may have been missed because of the transient nature of the phenomenon and the timing of the traces. ${ }^{23} \mathrm{It}$ is important to mention, that Derks et al study was on betamethasone only. ${ }^{23}$

Rotmensch et al recorded totally different results. ${ }^{24}$ They concluded a decrease in FHR STV on day 2, 48 hours after first dose. Rotmensch et al believed the cause of increased FHR variability in Dawes's study is the fact that $75 \%$ of the foetuses in the study were delivered by cesarean sections, as a consequence for foetal distress, indicating that they had been originally sensitive when steroids were administered. $^{22,24}$

Similarly, Subtil et al, concluded results that also go with Mulder et al analysis. ${ }^{18,23}$ They recorded an increase at 8 hours, and a decrease on the $56^{\text {th }}$ and $80^{\text {th }}$ hours. As a result, their study fell at equal distances between studies, and believed they made the conclusion in this area of FHR variability. But they on the other hand believe that the effects of betamethasone and dexamethasone are identical.
Regarding FHR LTV, only Magee et al recorded a significant decrease when combined the 2 groups. ${ }^{19}$ This may be explained by the repetition of the finding of decreased FHR LTV among studies of betamethasone.

Regarding accelerations, only Subtil et al and Rotmensch et al recorded a change in the acceleration number. ${ }^{18,24}$ On the second day, both studies recorded a significant decrease in the number of accelerations.

As regards to our study, unfortunately this is where we had our limitation, with the absence of CTG computerized numerical analysis. In our study, we could only document CTG changes if they were strikingly significant, as we relied on visual interpretation. In our results, we have not recorded any changes in FHR LTV, nor in accelerations, but there were 7 women with marked FHR STV patterns riddling their traces. These results coincide with previous studies that concluded increase in FHR STV, although our finding was around the $60^{\text {th }}$ hour; yet we didn't document an earlier change because of our study design. There might have been a numerical increase in the FHR STV in other women, but we documented the increase which marked a categorical difference (being defined as marked variability after being a moderate one). There is not a clear explanation for the discrepancy between our result and other studies' results. It could be validly argued, that with an increased sample size, the results might have differed since we had to use a non-parametric test for this variable, because of the absence of computerized numerical analysis.

The change in foetal count in most studies was absent. Except for Rotmensch et al and Magee et al, no other teams recorded a significant difference. ${ }^{19,24}$ Magee et al documented decrease in the first day relying on maternal perception during CTG recording, while Rotmensch et al documented it around the second day relying on live ultrasonography guided foetal movement counting which contrasts with our study. ${ }^{19,24}$

Our study design was different, since we relied on foetal counts all day long, but not as a total continuous count, but in 3 groups with a limit of 4 counts per group, as in the Sadovsky method. Despite this method being different, a significant decrease was recorded on the $2^{\text {nd }}$ day, confirming Rotmensch et al finding. ${ }^{24}$ The decrease nonetheless had no statistical correlation with any other parameters. We believe the decrease in the foetal movements is because of the presence of GR receptors in the raphe nuclei and the locus coeruleus, which play a role in the motor activity in the third trimester foetus, as Jacobs described. ${ }^{25}$

There are some limitations of the study. It remains a matter of conjecture whether the maternal subjections of foetal movements are true or not. The decrease on the second day might be of psychological effect, since women were told there will be a change in movements. We have no solid theory whether the use of the same methods used in the 
previous studies would have given different numbers or not. Our method couldn't have excluded foetal sleep cycles. It must be noted that the decrease in the foetal count was statistically significant, but not clinically significant, as the total number was all around more than 10 movements per day, according to Pearson and Weaver. ${ }^{26}$

\section{CONCLUSION}

We conclude from the study, that there are definitely cardiovascular changes that occur after dexamethasone administration, presented by increase in MCA blood flow and increase in FHR short term variability. However, these changes could not be strongly correlated with the decreased maternal perception of changes in foetal movements. Further studies should be done to detect more intricately the cardiovascular changes caused by dexamethasone.

Funding: No funding sources

Conflict of interest: None declared

Ethical approval: The study was approved by the Institutional Ethics Committee

\section{REFERENCES}

1. Roberts D, Dalziel SR. Antenatal corticosteroids for accelerating fetal lung maturation for women at risk of preterm birth. Cochrane Database Syst Rev. 2016;(3):CD004454.

2. Crowther CA, Harding JE. Repeat doses of prenatal corticosteroids for women at risk of preterm birth for preventing neonatal respiratory disease. Cochrane Database Syst Rev. 2007;3:CD003935.

3. Liggins GC, Howie RN. A controlled trial of antepartum glucocorticoid treatment for prevention of the respiratory distress syndrome. Pediatrics. 2002;50:515.

4. Maršál KS, Gennser S, Ohrlander AV. Fetal and neonatal breathing movements in man after betamethasone. Life Sci. 2009;17:449-54.

5. Katz MI, Meizner IS, Holcberg GE, Mazor MO, Hagay ZJ, Insler VA. Reduction or cessation of fetal movements after administration of steroids for enhancement of lung maturation. I. Clinical evaluation. Israel J Med Sci. 1988;24(1):5-9.

6. Doyle LW, Ehrenkranz RA, Halliday HL. Dexamethasone treatment in the first week of life for preventing bronchopulmonary dysplasia in preterm infants: a systematic review. Neonatol. 2010;98(3):217-24.

7. Wapner RJ, Sorokin Y, Thom EA, Johnson F, Dudley DJ, Spong CY, et al. Single versus weekly courses of antenatal corticosteroids: Evaluation of safety and efficacy. Am J Obstet Gynecol. 2006;195:633.

8. Jackson JR, Kleeman S, Doerzbacher M, Lambers DS. The effect of glucocorticosteroid administration on fetal movements and biophysical profile scores in normal pregnancies. J Matern Fet Neonat Med. 2003;13:50-3.
9. ACOG Practice Bulletin Number 145: Antepartum Fetal Surveillance, July 2014. Obstet Gynecol. 2014;124:182-92.

10. Sadovsky E. Monitoring fetal movement: A useful screening test. Contemp Obstet Gynecol. 1985;25(4):123-35.

11. Senat MV, Minoui S, Multon O, Fernandez $\mathrm{H}$, Frydman R, Ville Y. Effect of dexamethasone and betamethasone on fetal heart rate variability in preterm labour: a randomised study. $\mathrm{Br} \mathrm{J}$ Obstet Gynaecol. 2008;105:749-55.

12. Baud O, Foix-L'Helias L, Kaminski M, Audibert F, Jarreau PH, Papiernik E, et al. Antenatal glucocorticoid treatment and cystic periventricular leukomalacia in very premature infants. New Engl J Med. 2009;341:1190.

13. Rushmer RF, Baker DW, Johnson WL, Strandness DE. Clinical applications of a transcutaneous ultrasonic flow detector. JAMA. 2007;199(5):326-8.

14. Chitrit Y, Caubel P, Herrero R, Schwinte AL, Guillaumin D, Boulanger MC. Effects of maternal dexamethasone administration on fetal Doppler flow velocity waveforms. BJOG. 2010;107(4):501-7.

15. Urban R, Lemancewicz A, Przepieść J, Urban J, Kretowska M. Antenatal corticosteroid therapy: a comparative study of dexamethasone and betamethasone effects on fetal Doppler flow velocity waveforms. Eur J Obstet Gynecol Reprod Biol. 2005;120:170-4.

16. Senat MV, Ville Y. Effect of steroids on arterial Doppler in intrauterine growth retardation fetuses. Fetal Diagn Ther. 2015;15:36-40.

17. Fukuda S, Kato T, Kakita H, Yamada Y, Hussein MH, Kato I, et al. Hemodynamics of the cerebral arteries of infants with periventricular leukomalacia. Pediatrics. 2016;117(1):1-8.

18. Subtil D, Tiberghien P, Devos P, Therby D, Leclerc $\mathrm{G}$, Vaast $\mathrm{P}$, et al. Immediate and delayed effects of antenatal corticosteroids on fetal heart rate: a randomized trial that compares betamethasone acetate, betamethasone phosphate, and dexamethasone. Am J Obstet Gynecol. 2013;188:52431.

19. Magee LA, Dawes GS, Moulden M, Redman CWG. A randomised controlled comparison of betamethasone with dexamethasone: effects on the antenatal fetal heart rate. $\mathrm{Br} \mathrm{J}$ Obstet Gynaecol. 2012;104:1233-8.

20. Mushkat Y, Ascher-Landsberg J, Keidar R, Carmon E, Pauzner D, David MP. The effect of betamethasone versus dexamethasone on fetal biophysical parameters. Eur J Obstet Gynecol Reprod Biol. 2011;97:50-2.

21. Multon O, Senat MV, Minoui S, Hue MV, Frydman R, Ville Y. Effect of antenatal betamethasone and dexamethasone administration on fetal heart rate variability in growth-retarded fetuses. Fet Diagn Ther. 2013;12:170-7.

22. Dawes GS. Breathing before birth in animals and man. An essay in medicine. Physiol Med. 2004;290:557. 
23. Derks JB, Mulder EJH, Visser GHA. The effects of maternal betamethasone administration on the fetus. Br J Obstet Gynaecol. 2010;102:40-6.

24. Rotmensch S, Lev S, Kovo M, Efrat Z, Zahavi Z, Lev $\mathrm{N}$, et al. Effect of betamethasone administration on fetal heart rate tracing: a blinded longitudinal study. Fet Diagn Ther. 2012;20:371-6.

25. Jacobs BL. Overview of the activity of brain monoaminergic neurons across the sleep-wake cycle. In: Wauquicr A, Monti JM, Gaillard JM, eds. Sleep: neurotransmitters and neuromodulators. 1st edn. Raven Press; 1985:1-4.

26. Pearson JF, Weaver JB. Fetal activity and fetal wellbeing: an evaluation. Br Med J. 2006;1:1305-7.

Cite this article as: Alanwar A, Akl S, Hanafi S, Mohamed N. Effect of dexamethasone on daily fetal movement, umbilical and middle cerebral arteries Doppler and cardiotocogram. Int J Reprod Contracept Obstet Gynecol 2021;10:4041-7. 